\title{
THE VECTORCARDIOGRAM AND ELECTROCARDIOGRAM IN VENTRICULAR SEPTAL DEFECT
}

\author{
With Special Reference to the Diagnosis of Combined Ventricular Hypertrophy
}

\author{
BY \\ JONAS BEREGOVICH*, SELVYN BLEIFER, EPHRAIM DONOSO, AND \\ ARTHUR GRISHMAN \\ From the Divisions of Cardiology, Departments of Medicine and Pediatrics, The Mount Sinai Hospital, \\ New York, U.S.A. \\ Received April 10, 1959
}

Since the original description of ventricular septal defect by Roger in 1879, the clinical and pathological concepts of this malformation have undergone a striking metamorphosis. Originally considered a benign lesion except for the threat of bacterial endocarditis, it is now considered a serious malformation with a relatively poor prognosis (Selzer, 1949; Downing and Goldberg, 1956; Brotmacher and Campbell, 1958) except for small defects with insignificant shunts. The classification of Taussig (1947) into high defects associated with symptoms and low defects with classical signs and few or no symptoms has been challenged (Selzer, 1949). Most defects are located in the membranous septum but the most important factors are the size of the defect and the pulmonary vascular resistance (Selzer, 1949; Wood et al., 1954; Mannheimer et al., 1957). Thus, the development of pulmonary hypertension with cyanosis, hæmoptysis, and death has been reported even with large muscular defects (Heath et al., 1956).

With moderate and large sized defects a common denominator at post-mortem examination is the existence of combined ventricular hypertrophy, since both ventricles are overburdened. However, one can only infrequently diagnose combined ventricular hypertrophy by the electrocardiogram. Some of the existing criteria for this diagnosis do not apply to children (Pagnoni and Goodwin, 1952; Rosenman et al., 1950). There are no established vectorcardiographic criteria for the presence of combined ventricular hypertrophy. Whipple and Levine (1955) reported the vectorcardiograms in eight patients with rheumatic heart disease who had combined hypertrophy post mortem. Wolff et al. (1953), in a review of vectorcardiography briefly mentions the vectorcardiogram in congenital heart disease with combined ventricular hypertrophy. Cabrera et al. (1958) has described several vectorcardiographic patterns observed in patients with ventricular septal defect.

Thirty-five proven cases of ventricular septal defect have been reviewed (six with post-mortem examination) with a dual purpose in mind: (1) to attempt to correlate the heterogeneous electrocardiograms of this malformation with pressures or the presence of associated lesions such as aortic regurgitation and pulmonary stenosis, and (2) to attempt to correlate the various vectorcardiographic patterns observed with the same data and possibly to establish vectorcardiographic criteria for combined ventricular hypertrophy in congenital heart disease.

\section{METHODS AND MATERIAL}

Thirty-five patients were seen in the congenital heart clinic and wards of The Mount Sinai Hospital in the period between 1953-1958. Selection was made on the basis of a complete 
history, physical examination, X-rays, electrocardiogram, vectorcardiogram, and right heart catheterization.

Thirty-two patients were submitted to cardiac catheterization and all but three had over a one volume percentage $\mathrm{O}_{2}$ step up at the right ventricular level. These three were included because the rest of the data was considered diagnostic of ventricular septal defect.

There were six patients in whom post-mortem examination was performed. Three of these (all less than one year old) did not have cardiac catheterization.

The age of the patients was between 4 months and 30 years (Table I). There were 13 male and 22 female patients in the series.

TABLE I

Ventricular Septal Defect

Age Distribution

\begin{tabular}{|c|c|c|c|c|}
\hline \multicolumn{4}{|c|}{ Age group (years) } & Cases \\
\hline $\begin{array}{l}\text { Less than } \\
\text { Greater than }\end{array}$ & $\begin{array}{r}1 \\
1-4 \\
5-9 \\
10-14 \\
15-19 \\
20\end{array}$ & $\begin{array}{l}\ldots \\
\ldots \\
\ldots \\
\ldots \\
\cdots\end{array}$ & $\begin{array}{l}\ldots \\
\ldots \\
\ldots \\
\ldots \\
\ldots\end{array}$ & $\begin{array}{r}4 \\
6 \\
9 \\
10 \\
4 \\
2 \\
35\end{array}$ \\
\hline
\end{tabular}

The electrocardiograms were obtained with the direct-writing three-channel Technicon or Sanborn Viso-cardiette. Double paper speed $(50 \mathrm{~mm}$./sec.) was used in many instances. The vectorcardiograms were obtained with the Sanborn Viso-scope and Vector system or the Technicon Vectorscope, using the cube method of electrode placement (Grishman and Scherlis, 1952).

The electrocardiographic diagnosis of right ventricular hypertrophy was based on the criteria established by Sokolow and Lyon (1949), Goodwin (1952), and Milnor (1957). Right ventricular hypertrophy in the presence of right bundle-branch block was diagnosed if the electrocardiogram conformed to the criteria of Wilson et al. (1954) and Barker and Valencia (1949). Left ventricular hypertrophy was considered to be present if the criteria of Sokolow and Lyon (1949) or Pagnoni and Goodwin (1952) were fulfilled. The criteria of Rosenman et al. (1950) or Pagnoni and Goodwin (1952) were applied for the diagnosis of combined ventricular hypertrophy. Ziegler's tables (1951) were also used for the analysis of the normal $R$ waves and $R / S$ ratios in the præcordial leads.

The horizontal, sagittal, and frontal planes of the vectorcardiograms were analysed for spatial orientation, configuration, and direction of inscription of the QRSsE and TsE loops.

\section{Classification}

From the clinical, hæmodynamic, and electrophysiological data it was evident that there was no uniformity in these patients, and in fact there was great diversity in the findings that they exhibited. The series has been divided and we shall consider separately associated lesions that place an additional burden on the right ventricle (infundibular pulmonary stenosis), or left ventricle (aortic regurgitation) in order to assess the possible effects of these lesions on the electrocardiogram and vectorcardiogram. The patients with pure ventricular septal defects were considered to be mild, moderate, or severe according to the concepts of Wood et al. (1954) which are based on heart size, pressures, size of the shunt, and the electrocardiogram.

Pure Ventricular Septal Defect $(27$ cases). All of these patients were considered to be examples of isolated ventricular septal defect with normal aortic root, in which the clinical, hæmodynamic and post-mortem studies ( 3 cases) showed no evidence of associated malformations. We have 
considered cases to be mild if the X-rays and electrocardiogram and the pressures in the right ventricle and pulmonary artery were within normal limits (11 cases). Cases were considered to be moderate or severe when there was evidence of cardiac enlargement, electrocardiographic evidence of hypertrophy of the right or left ventricle, and/or high pressures in the right ventricle and pulmonary artery (16 cases). The moderate and severe cases are grouped together for discussion purposes, as it was difficult to separate them on the basis of the information available. For example, patients who had very large hearts or were symptomatic were considered to have moderate forms of the disease despite right ventricular and pulmonary artery pressures that were within normal limits. Patients who died in infancy were considered to have severe forms of the disease ( 3 cases).

Ventricular Septal Defect with Aortic Regurgitation (3 cases). A high pitched decrescendo diastolic murmur along the left sternal border accompanied by a water-hammer pulse and a wide pulse pressure were present in all. Two of these patients were submitted to thoracotomy with a pre-operative diagnosis of patent ductus arteriosus which was not confirmed.

Ventricular Septal Defect with Infundibular Pulmonary Stenosis (5 cases). Right heart catheterization revealed the presence of an infundibular chamber in five patients, with three post-mortem confirmations.

\section{RESULTS}

The Electrocardiogram and Vectorcardiogram in Pure Ventricular Septal Defect

Mild Cases. Table II lists the electrocardiographic and vectorcardiographic diagnosis together

TABLE II

Pure Ventricular Septal Defect (Mild Cases)

\begin{tabular}{|c|c|c|c|c|c|c|}
\hline Case & $\begin{array}{c}\text { Age } \\
\text { (years) }\end{array}$ & $\begin{array}{l}\text { RV press. } \\
\text { (mm. Hg) }\end{array}$ & $\begin{array}{l}\text { PA press. } \\
\text { (mm. Hg) }\end{array}$ & $\begin{array}{l}\text { RV step-up } \\
\left(\mathrm{O}_{2} \text { vol. } \%\right)\end{array}$ & ECG * & VCG \\
\hline $\begin{array}{l}\text { 1-P.C. } \\
\text { 2-R.P. } \\
\text { 3-J.M. } \\
\text { 4-M.O. } \\
\text { 5-D.B. } \\
\text { 6-E.M. } \\
\text { 7-T.B. } \\
\text { 8-D.G. } \\
\text { 9-J.K. } \\
\text { 10-M.C. } \\
\text { 11-L.B. }\end{array}$ & $\begin{array}{r}9 \\
12 \\
10 \\
9 \\
7 \\
17 \\
15 \\
5 \\
3 \\
10 \\
30\end{array}$ & $\begin{array}{c}23 / 2 \\
30 / 2 \\
33 / 6 \\
30 / 0 \\
18 / 5 \\
31 / 8 \\
30 / 5 \\
34 / 0 \\
32 / 0 \\
35 / 0 \\
-\end{array}$ & $\begin{array}{l}22 / 4 \\
22 / 10 \\
25 / 9 \\
25 / 7 \\
20 / 10 \\
33 / 10 \\
25 / 6 \\
30 / 12 \\
29 / 12 \\
24 / 6 \\
-\end{array}$ & $\begin{array}{l}2 \cdot 8 \\
0 \cdot 6 \\
1 \\
0 \cdot 6 \\
1 \\
1 \cdot 2 \\
1 \\
1 \cdot 5 \\
2 \\
2 \\
-\end{array}$ & $\begin{array}{l}\text { Normal } \\
\text { Normal } \\
\text { Normal } \\
\text { Normal } \\
\text { Normal } \\
\text { Normal } \\
\text { Normal } \\
\text { LVH? } \\
\text { RBBB } \\
\text { RBBB } \\
\text { Normal }\end{array}$ & $\begin{array}{l}\text { Normal } \\
\text { Normal } \\
\text { Normal } \\
\text { Normal } \\
\text { Normal } \\
\text { Normal } \\
\text { Normal } \\
\text { Normal } \\
\text { RBBB } \\
\text { RBBB } \\
\text { BVH? } \dagger\end{array}$ \\
\hline
\end{tabular}

* Ventricular complex. (QRS-ST and T.)

† Biventricular hypertrophy.

with other data in the eleven cases of mild ventricular septal defect. In eight the electrocardiogram and vectorcardiogram were normal (Fig. 1). Incomplete right bundle-branch block pattern was present in two patients (Cases 9, and 10) with the QRS duration 0.09 and 0.11 sec. respectively. In one (Case 8) there was an $R$ wave of $66 \mathrm{~mm}$. in V5 without any other abnormality to confirm a diagnosis of left ventricular hypertrophy and, therefore, we have questioned this diagnosis: in this case the vectorcardiogram was normal. In Case 11, the electrocardiogram was normal, but the vectorcardiogram showed a pattern that we believe is highly suggestive of combined ventricular hypertrophy (Fig. 2). This will be discussed later.

Moderate and Severe Cases. Table III shows the electrocardiographic, vectorcardiographic, and other data in this group of patients. In 12 of these 16 cases there was electrocardiographic evidence 

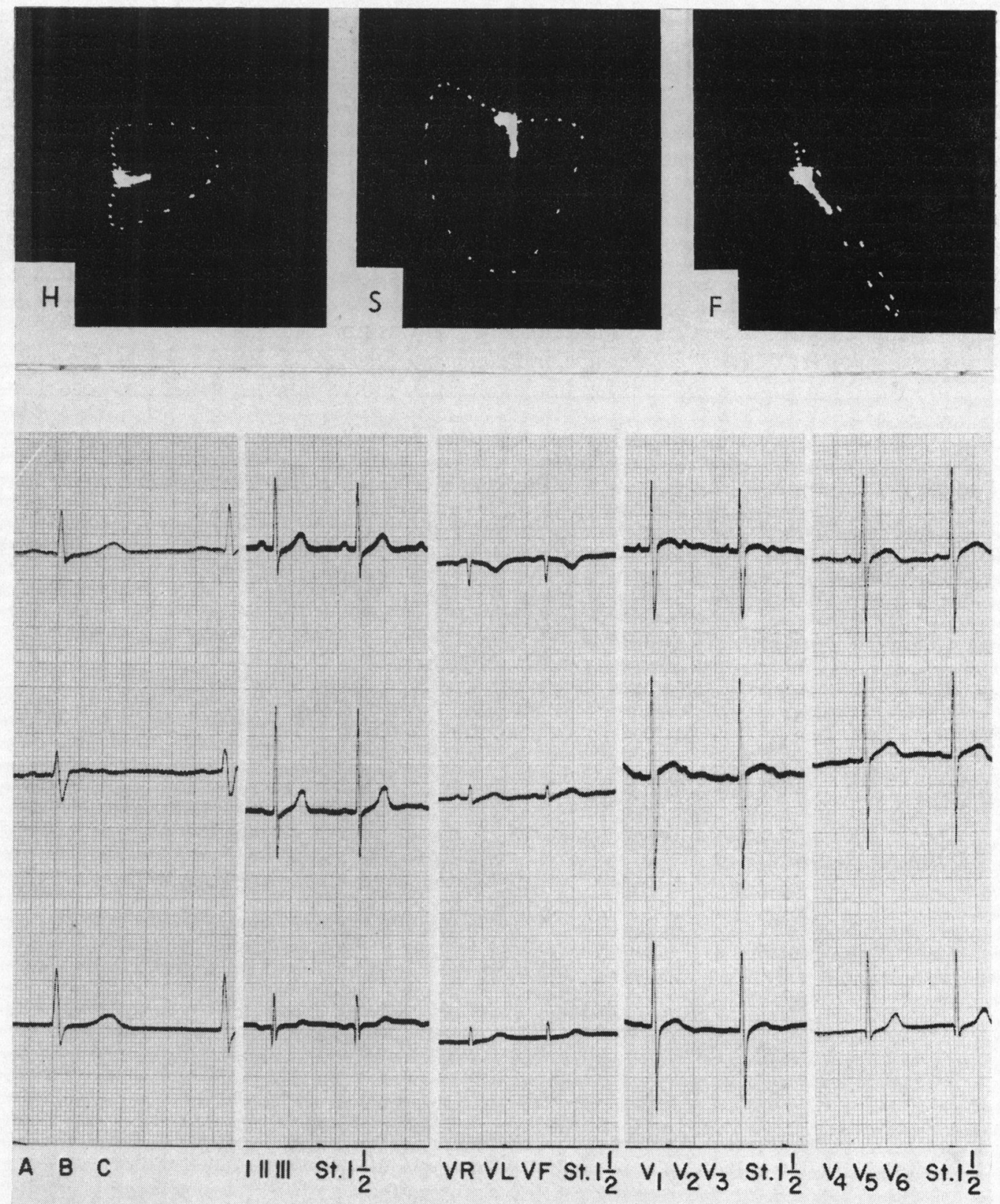

M. 0.9 yrs.

FIG. 1.-Normal vectorcardiogram and electrocardiogram in a 9-year-old boy with a mild ventricular septal defect. Case 4. The vectorcardiographic tracing shows the $(H)$ horizontal, $(S)$ right sagittal, and $(F)$ frontal plane. The sense of rotation of the QRS sE loop is indicated by the blunt end of the tear drop which points in the direction of inscription. The electrocardiogram shows the conventional 12 leads. St. $1 \frac{1}{2}$ indicates one and one-half times the usual standardization. A, B, and C are the vector component bipolar leads of the cube reference system. 

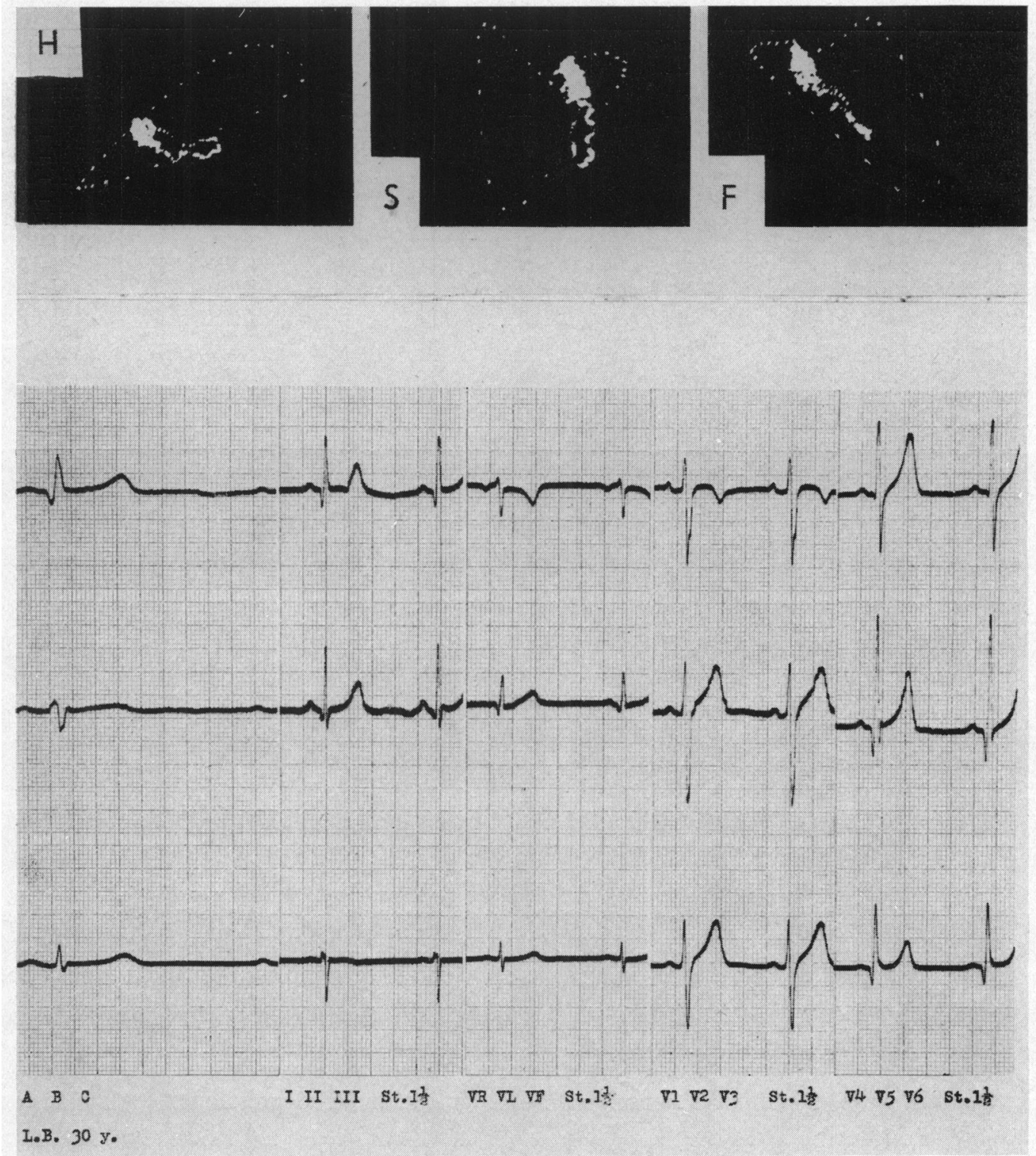

FIG. 2.-Vectorcardiographic pattern of combined ventricular hypertrophy (type A), occurring in a 30-yearold man with a mild ventricular septal defect. Case 11. The horizontal plane shows a large initial segment directed to the right and anteriorly, and then the loop is oriented to the left and posteriorly, with a counterclockwise rotation. The electrocardiogram is within normal limits (see Fig. 1). 
TABLE III

Pure Ventricular Septal Defect (Moderate and Severe Cases)

\begin{tabular}{|c|c|c|c|c|c|c|}
\hline Case & $\begin{array}{c}\text { Age } \\
\text { (years) }\end{array}$ & $\begin{array}{l}\text { RV press. } \\
\text { (mm. Hg) }\end{array}$ & $\begin{array}{l}\text { PA press. } \\
\text { (mm. Hg) }\end{array}$ & $\begin{array}{l}\text { RV step-up } \\
\left(\mathrm{O}_{2} \text { vol. } \%\right)\end{array}$ & $\begin{array}{l}\text { Electro- } \\
\text { cardiogram }\end{array}$ & $\begin{array}{l}\text { Vector- } \\
\text { cardiogram }\end{array}$ \\
\hline $\begin{array}{l}\text { 12-W.N, } \\
\text { 13-M.D. } \\
\text { 14-M.A. } \\
\text { 15-C.M. } \\
\text { 16-R.O. } \\
\text { 17-A.G. } \\
\text { 18-M.K. } \\
\text { 19-H.L. } \\
\text { 20-E.B. } \\
\text { 21-L.A. } \\
\text { 22-D.O. } \\
\text { 23-M.D. } \\
\text { 24-B.R. }\end{array}$ & $\begin{array}{c}4 \\
7 \mathrm{mo} \\
7 \mathrm{mo} \\
4 \mathrm{mo} \\
13 \\
8 \\
10 \\
2 \frac{1}{2} \\
11 \\
5 \\
1 \frac{1}{2} \\
9 \\
13\end{array}$ & $\begin{array}{l}90 / 10 \\
\overline{-} \\
\overline{-} \\
42 / 8 \\
33 / 2 \\
106 / 6 \\
69 / 8 \\
51 / 0 \\
25 / 6 \\
60 / 5 \\
96 / 4 \\
97 / 8\end{array}$ & $\begin{array}{c}82 / 43 \\
85 / 35 \\
\overline{-} \\
54 / 30 \\
30 / 11 \\
102 / 52 \\
54 / 12 \\
36 / 11 \\
25 / 8 \\
50 / 12 \\
108 / 49 \\
90 / 39\end{array}$ & $\begin{array}{l}2 \\
3 \\
- \\
3 \\
2 \\
4 \\
2 \cdot 3 \\
3 \cdot 4 \\
1 \cdot 7 \\
3 \cdot 3 \\
3 \cdot 2 \\
2 \cdot 3\end{array}$ & $\begin{array}{l}\text { RVH-LVH } \\
\text { Normal* } \\
\text { Normal } \\
\text { Normal } \\
\text { RVH-LVH } \\
\text { RVH-LVH } \\
\text { RVH } \\
\text { RVH-LVH* } \\
\text { RVH-LVH } \\
\text { RBBB } \\
\text { RVH-LVH } \\
\text { RVH-LVH } \\
\text { RVH-LVH* } \\
\text { RBBB } \\
\text { RVH }\end{array}$ & $\begin{array}{l}\text { Normal } \\
\text { Normal } \\
\text { Normal } \\
\text { Normal } \\
\text { RVH-LVH* } \\
\text { RVH-LVH* } \\
\text { RVH-LVH* } \\
\text { RVH-LVH* } \\
\text { RVH-LVH* } \\
\text { RVH-LVH* } \\
\text { RVH-LVH* } \\
\text { RVH-LVH* } \\
\text { RVH-LVH* } \\
\text { Cond. delay } \\
\text { RVH }\end{array}$ \\
\hline $\begin{array}{l}\text { 26-G.W. } \\
27-C . F . \dagger\end{array}$ & $\begin{array}{l}13 \\
8 \mathrm{mo}\end{array}$ & $35 / 3$ & $\begin{array}{l}75 / 35 \\
- \\
-\end{array}$ & $1 \cdot 3$ & $\begin{array}{l}\text { RVH-LVH } \\
\text { RBBB } \\
\text { RVH-LVH } \\
\text { RVH-LVH* }\end{array}$ & $\begin{array}{l}\text { RVH-LVH* } \\
\text { RVH } \\
\text { RVH }\end{array}$ \\
\hline
\end{tabular}

RVH: Right ventricular hypertrophy.

LVH: Left ventricular hypertrophy.

* Questionable diagnosis of left ventricular hypertrophy.

$\dagger$ Post-mortem examination.

of right ventricular hypertrophy. The electrocardiographic criteria that we found to be of major importance for this diagnosis were the following.

(1) $\mathrm{R} / \mathrm{S}$ or $\mathrm{R}^{\prime} / \mathrm{S}$ ratio in $\mathrm{V} 1$ greater than 1 in patients over five years of age. Below five years the $\mathrm{R} / \mathrm{S}$ ratio had to be greater than the upper limits of normal for the age group according to Ziegler (1951). (All 12 cases fit this criteria.)

(2) Intrinsicoid deflection in V1 greater than $0.03 \mathrm{sec}$. (4 cases.)

(3) Deep S waves in V5 or V6. (7 cases.)

(4) $R$ wave or $R^{\prime}$ in aVR greater than the $Q$ or $S$ wave in the same lead. (3 cases.)

Of these 12 cases, there were 9 in which we found two or more of the above criteria. In the other three cases only the first criterion (which is the most important) was satisfied.

In 11 of these 12 patients, a certain or probable diagnosis of left ventricular hypertrophy was made in addition. Electrocardiographically right ventricular hypertrophy appeared to be more prominent and, in its presence, the following signs appeared to be significant for the diagnosis of left ventricular hypertrophy.

(1) Left axis deviation of 0 degrees or less. (3 cases.)

(2) R wave in V5 or V6 of $34 \mathrm{~mm}$. or greater; or $25 \mathrm{~mm}$. or greater when accompanied by a small $\mathrm{S}$ wave (less than $2.5 \mathrm{~mm}$.) or $\mathrm{S}-\mathrm{T}$ segment and $\mathrm{T}$ depressions. (All $11 \mathrm{met}$ this criteria.)

(3) Intrinsicoid deflection in V5 or V6 greater than 0.05 sec. (1 case.)

(4) An $R$ wave in aVL greater than $15 \mathrm{~mm}$. when accompanied by left axis deviation. (3 cases.)

In eight of these patients a diagnosis of left ventricular hypertrophy was based on two or more of the above mentioned criteria. In the other three the only criterion for left ventricular hypertrophy was a tall $\mathrm{R}$ wave in V5 or V6, and in these cases the diagnosis is indicated with a question mark in table III.

In the vectorcardiograms all twelve showed clear indications for a diagnosis of right ventricular hypertrophy. This was based on an anterior displacement of the QRSsÊ loop in the horizontal 
and sagittal plane. In 10 of these (Cases 16-25) there were associated findings that differed from the typical pattern described for pure right ventricular hypertrophy (Grishman and Scherlis, 1952). We believe these findings indicate the presence of associated left ventricular hypertrophy.

In four instances (Cases 16 to 19), the QRSsE loop in the horizontal plane was anteriorly oriented. Contrary to the usual pattern described for RVH there was counter-clockwise inscription of the loop in the horizontal plane (Fig. 3).

In four others (Cases 20-23) there was a figure of eight configuration of the QRSsE loop in the horizontal plane, with the terminal limb clockwise and displaced anteriorly to the E point (Fig. 4). Although this configuration in the horizontal plane is similar to that found in other conditions associated with only right ventricular hypertrophy (e.g. atrial septal defect) (Braunwald et al., 1955), in our cases the QRSsE loop in the frontal plane was displaced to the left and inscribed counterclockwise, a finding not present in the usual pattern of pure right ventricular hypertrophy.

In two others (Cases 24,25 ) there was a clockwise rotation of the anteriorly displaced QRSsE loop in the horizontal plane, but in the frontal plane there was a leftward displacement and counterclockwise rotation of the loop which differentiated these cases from one of the classical patterns of pure right ventricular hypertrophy (Fig. 5).

Four patients (Cases 12 to 15 ) had anterior displacement of the QRSsE loop in the horizontal plane. However, they were young (three below 7 months) and the vectorcardiogram was not outside of the wide range of normal patterns that have been observed in this age group. In the three examined at autopsy (Cases 14, 15, 27) a large ventricular septal defect was found. In one (Case 15) the defect was in the muscular septum but very large $(11 \mathrm{~mm}$.) considering the age of the patient (4 months). There was dilatation of the pulmonary artery and left atrium and biventricular hypertrophy in all three. The right ventricular hypertrophy was greater than the left ventricular hypertrophy and the thickness of the right ventricle compared with the left was $6 / 6,9 / 11$, and $7 / 9 \mathrm{~mm}$. respectively.

TABLE IV

Ventricular Septal Defect and Aortic Regurgitation

\begin{tabular}{|c|c|c|c|c|c|c|c|}
\hline Case & $\begin{array}{c}\text { Age } \\
\text { (years) }\end{array}$ & $\underset{(\mathrm{mm} . \mathrm{Hg})}{\text { BP }}$ & $\begin{array}{l}\text { RV press. } \\
(\mathrm{mm} . \mathrm{Hg})\end{array}$ & $\begin{array}{l}\text { PA press. } \\
(\mathrm{mm} . \mathrm{Hg})\end{array}$ & $\begin{array}{l}\text { RV step-up } \\
\left(\mathrm{O}_{2} \text { vol. } \%\right)\end{array}$ & $\begin{array}{c}\text { Electro- } \\
\text { cardiogram }\end{array}$ & $\begin{array}{c}\text { Vector- } \\
\text { cardiogram }\end{array}$ \\
\hline $\begin{array}{l}\text { 28-A.T.* } \\
\text { 29-M.L. } \\
\text { 30-P.D.* }\end{array}$ & $\begin{array}{l}16 \\
13 \\
13\end{array}$ & $\begin{array}{l}120 / 40-0 \\
120 / 50-20 \\
110 / 40\end{array}$ & $\begin{array}{l}26 / 6 \\
22 / 0 \\
50 / 0\end{array}$ & $\begin{array}{l}26 / 2 \\
21 / 13 \\
40 / 15\end{array}$ & $\frac{0.8}{3}$ & $\begin{array}{l}\text { Normal } \\
\text { LVH } \\
\text { RBBB } \\
\text { RVH† }\end{array}$ & $\begin{array}{l}\text { Normal } \\
\text { Normal } \\
\text { RBBB }\end{array}$ \\
\hline
\end{tabular}

* Operated for presumed patent ductus arteriosus.

† Questionable diagnosis.

Ventricular Septal Defect with Aortic Regurgitation. Table IV shows the pertinent data in three patients with ventricular septal defect and aortic regurgitation. The electrocardiograms and vectorcardiograms do not show a specific or constant pattern that serves to differentiate this group. Despite the additional burden imposed on the left ventricle, in only one case did the electrocardiogram show evidence of left ventricular hypertrophy.

Ventricular Septal Defect with Infundibular Pulmonary Stenosis. Table V shows the pertinent data in five patients with this combination. Two (Cases 31, 32) show two of the vectorcardiographic patterns previously described which we consider as evidence of combined ventricular hypertrophy. Three patients (Cases 33-35) showed a typical vectorcardiographic pattern of pure right ventricular hypertrophy, namely anterior displacement and clockwise rotation of the QRSsE loop in the horizontal plane (Fig. 6). Post-mortem examination in these three showed a large ventricular septal defect, infundibular pulmonary stenosis, and a normal aortic root. All showed 

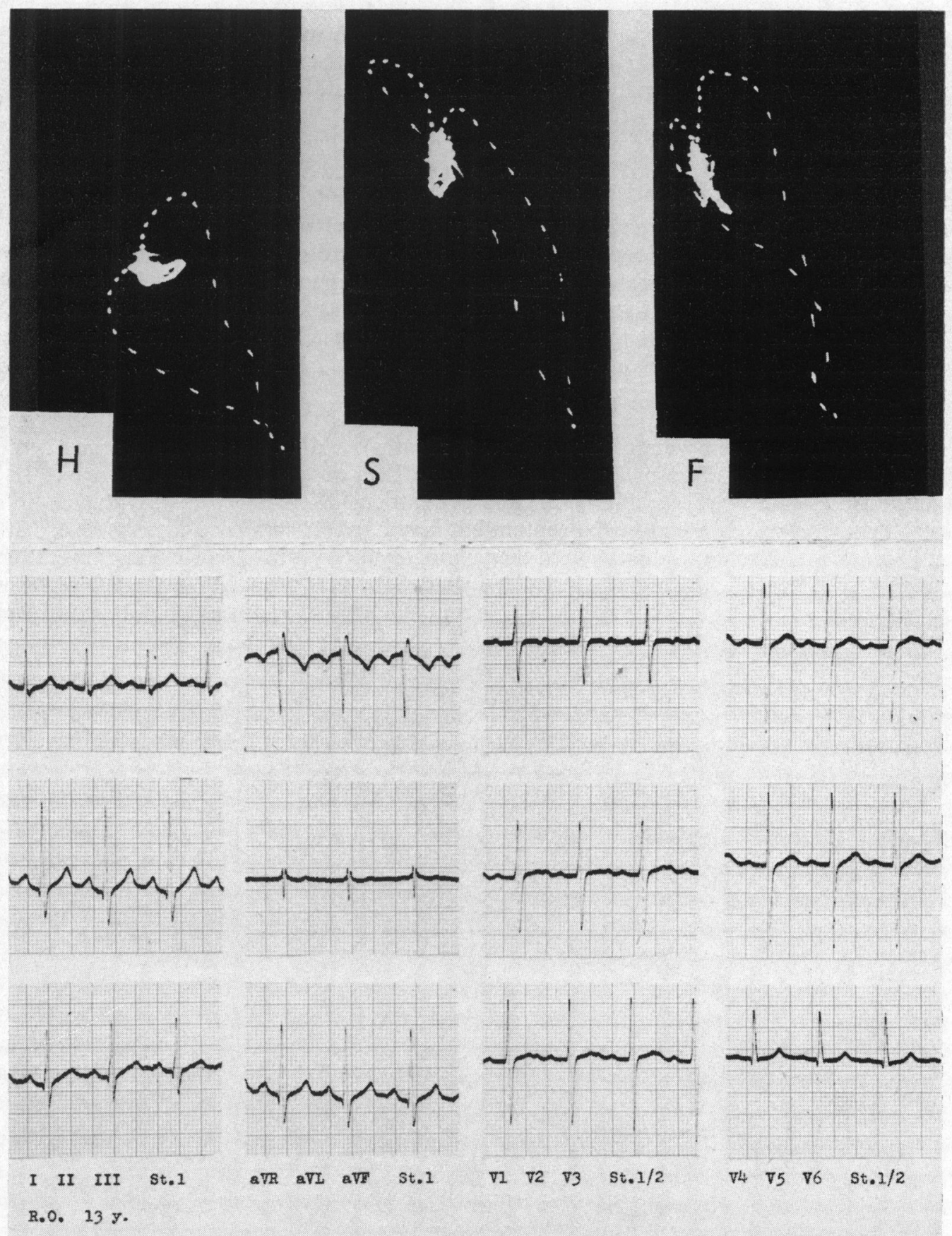

FIG. 3.-Vectorcardiographic pattern of combined ventricular hypertrophy (type B) occurring in a 13-yearold boy, with a moderate ventricular septal defect. Case 16. The horizontal plane is characterized by a large anterior displacement of the QRS $\mathrm{sE}$ loop, and with counterclockwise rotation. The electrocardiogram suggests also combined ventricular hypertrophy: $R / S$ in V1 equals 1 , with the $R$ wave measuring $14 \mathrm{~mm}$. and deep $S$ waves in V5. At the same time, there are relatively tall $R$ waves in V6. 

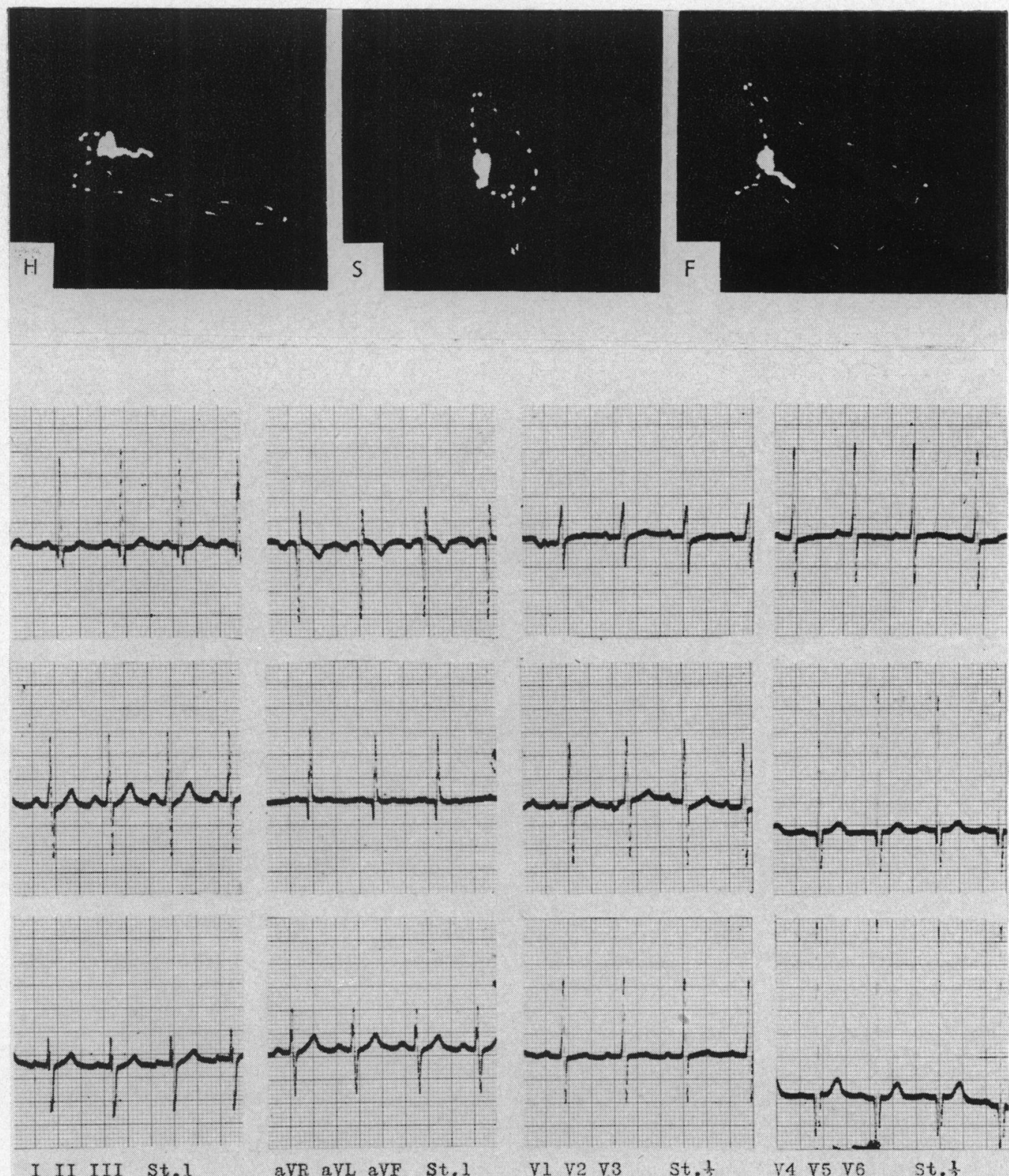

V1 V2 V3

St. $\frac{1}{2}$

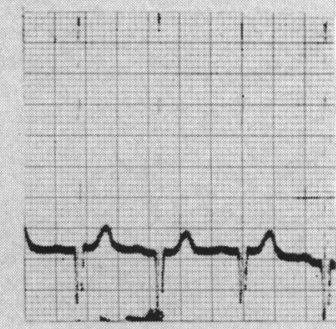
I II III St.l
D.0. $18 \mathrm{mo}$.

aVR aVL aVF St.1

FIG. 4.-Vectorcardiographic pattern (type C) of combined ventricular hypertrophy. Case 22. The horizontal plane shows a figure of eight QRS sE loop as is observed frequently in right ventricular hypertrophy; however, the frontal plane QRS $s \hat{E}$ loop is displaced to the left and the sense of rotation is counterclockwise, as with left ventricular hypertrophy. The electrocardiogram is a typical pattern of combined ventricular hypertrophy: the $R / S$ in $V 1$ is greater than 1 , with an intrinsicoid deflection of $0.035 \mathrm{sec}$. In addition, there is left axis deviation, a tall $R$ with a flattened $T$ in aVL and extremely tall $\mathbf{R}$ waves in V5-6. 

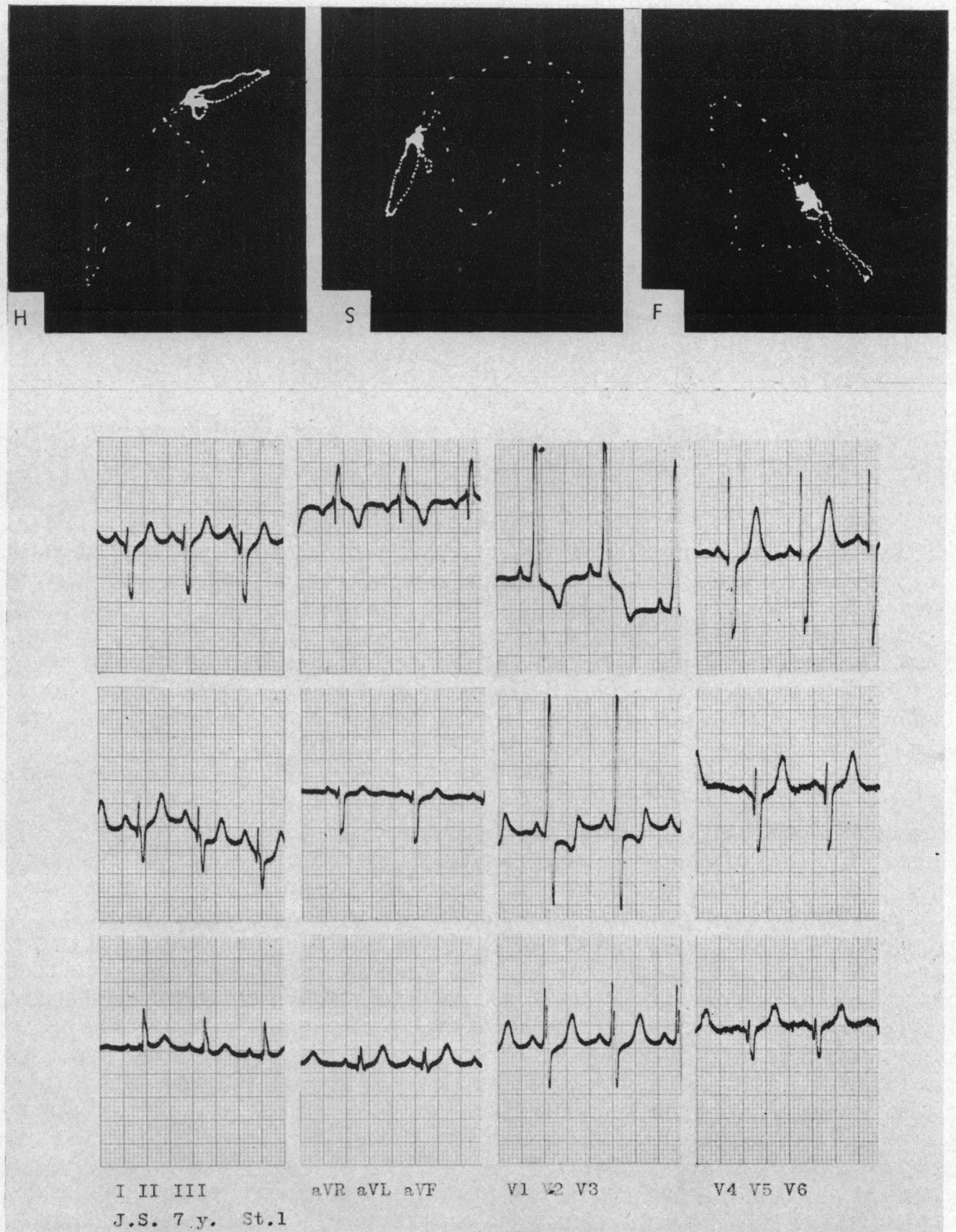

aVR aVL aVT

V1 2 V3

$\begin{array}{lll}V 4 & V 5 & \text { V6 }\end{array}$

FIG. 6.-Vectorcardiogram and electrocardiogram of a 7-year-old boy with ventricular septal defect and infundibular pulmonary stenosis. Both show right ventricular hypertrophy. Case 35. 
TABLE V

Ventricular Septal Defect and Infundibular Pulmonary Stenosis

\begin{tabular}{|c|c|c|c|c|c|c|}
\hline Case & $\underset{\text { (years) }}{\text { Age }}$ & $\begin{array}{l}\text { RV press. } \\
(\mathrm{mm} . \mathrm{Hg})\end{array}$ & $\begin{array}{l}\text { PA press. } \\
(\mathrm{mm} . \mathrm{Hg})\end{array}$ & $\begin{array}{l}\text { RV step-up } \\
\left(\mathrm{O}_{2} \text { vol. } \%\right)\end{array}$ & $\begin{array}{l}\text { Electro- } \\
\text { cardiogram }\end{array}$ & $\begin{array}{l}\text { Vector- } \\
\text { cardiogram }\end{array}$ \\
\hline 31-C.B. & 19 & $52 / 8$ & $24 / 7$ & $1 \cdot 7$ & LVH $\ddagger$ & LVH-RVH $\ddagger$ \\
\hline 32-C.R. & 5 & $\begin{array}{l}80 / 5 \\
40 / 5^{*}\end{array}$ & $38 / 15$ & $3 \cdot 3$ & LVH $\ddagger$ & RVH-LVH \\
\hline 33-C.C. $\dagger$ & 3 & $\begin{array}{l}105 / 6 \\
59 / 9 *\end{array}$ & $43 / 10$ & $2 \cdot 6$ & RVH-LVH $\ddagger$ & RVH \\
\hline 34-R.F. $\dagger$ & $3 \frac{1}{2}$ & $120 / 6$ & $33 / 11$ & $1 \cdot 1$ & RVH & RVH \\
\hline 35-J.S. $†$ & 7 & - & - & - & $\begin{array}{l}\text { RVH } \\
\text { RBBB }\end{array}$ & $\begin{array}{l}\text { RVH } \\
\text { Cond. delay }\end{array}$ \\
\hline
\end{tabular}

* Infundibular chamber.

$\dagger$ Cases with autopsy.

$\ddagger$ Questionable diagnosis.

combined ventricular hypertrophy with predominantly right ventricular hypertrophy. The thickness of the right ventricle compared to the left was $5 / 10,12 \cdot 5 / 15$, and $7 \cdot 5 / 10 \mathrm{~mm}$. respectively.

\section{Associated Electrocardiographic Findings}

All 35 patients showed a normal sinus rhythm and normal atrio ventricular conduction. In five there was minimal to moderate left axis deviation, in seven minimal to moderate right axis deviation, and in three there was a concordant $S$ pattern in the standard leads, but the distribution of these findings showed so much overlap that it was of no additional value. Normal axis was found in 20 patients. In four instances there was electrocardiographic evidence of left atrial enlargement and in two of right atrial enlargement. S-T segment and T wave abnormalities were also analysed but in the majority there were no deviations from the normal, even when there was evidence of left and/or right ventricular hypertrophy.

\section{Discussion}

There were five different electrocardiographic patterns observed in our patients.

Normal. Of 11 instances of a normal electrocardiogram 7 occurred in patients classified as having a mild ventricular septal defect. This pattern was observed in one patient with associated aortic regurgitation, but with normal right ventricular and pulmonary artery pressures and a small shunt. Three infants, all below seven months of age, had borderline electrocardiograms: they had severe forms of the defect and two died. The normal right ventricular preponderance in infants and the wide variations considered normal make an electrocardiographic diagnosis particularly difficult and we considered the electrocardiogram normal in these cases. Excluding infants, a normal electrocardiogram was invariably associated with a mild septal defect.

Incomplete right bundle-branch block. This pattern was observed in four instances and in itself cannot be considered necessarily abnormal in children. It occurred twice with mild defects, once with associated aortic regurgitation, and once in a moderately severe case in which the vectorcardiogram disclosed right ventricular hypertrophy.

Combined ventricular hypertrophy. This pattern was observed in 11 patients with moderate or severe ventricular septal defects. It occurred in one patient with infundibular pulmonary stenosis.

Right ventricular hypertrophy. Of three patients with an electrocardiographic pattern of right ventricular hypertrophy, two had infundibular pulmonary stenosis and the other severe pulmonary hypertension.

Left ventricular hypertrophy. Clear evidence of left ventricular hypertrophy occurred in only one 
patient who had an associated aortic regurgitation. One patient had high voltage of the $\mathrm{R}$ wave in V5 and V6 and another had marked left axis deviation (minus 60 degrees) as the only suggestion for left ventricular hypertrophy. The presence of high voltage in V5 or V6 as an isolated finding in children was not considered to be diagnostic of left ventricular hypertrophy.

Other investigators have described similar electrocardiographic patterns in patients with ventricular septal defects. They also found normal electrocardiograms in the mild cases and combined hypertrophy associated with large defects. Right ventricular hypertrophy has been described in the presence of pulmonary stenosis or pulmonary hypertension (Downing and Goldberg, 1956; Wood et al., 1954) and left ventricular hypertrophy with large shunts or with aortic regurgitation (Fyler et al., 1958; Wood et al., 1954). The electrocardiographic diagnosis of combined ventricular hypertrophy is a difficult one and has been the subject of considerable controversy and discussion (Levine and Phillips, 1951; Lipsett and Zinn, 1953; Marsico et al., 1955).

In general, the diagnosis of ventricular hypertrophy is based on an alteration of the normal balance of electrical forces. When both ventricles are enlarged to an equal degree, the balance of forces may remain within the normal range. When the right or left ventricle is disproportionately enlarged, the balance of forces is so altered as to cause predominance of one ventricle, which is interpreted electrophysiologically as indicating hypertrophy of that ventricle. This concept is supported by the finding of a variety of electrocardiographic patterns in patients with a lesion causing combined ventricular hypertrophy. The degree of enlargement of the ventricles in ventricular septal defect varies considerably with such factors as the size of the defect, the pulmonary vascular resistance, and other lesions that burden one ventricle more than the other.

Attempts to establish electrocardiographic criteria for combined ventricular hypertrophy have been made by Pagnoni and Goodwin (1952) and Rosenman et al. (1950). However, the patients studied were generally adults with acquired heart disease in whom (although there were factors leading to right ventricular enlargement) generally the left ventricle was disproportionately enlarged. For these reasons such criteria may not be applicable to our patients who, for the most part, were children with congenital heart disease. In our cases when a diagnosis of combined hypertrophy could be made, the predominant enlargement occurred in the right ventricle and the difficulty arose in diagnosing left ventricular hypertrophy in the presence of right ventricular hypertrophy. Under these circumstances the criteria for left ventricular hypertrophy in the presence of right ventricular hypertrophy, previously mentioned, were particularly useful. We have stated that high voltage of the R wave in V5 or V6 alone is of little value in the diagnosis of left hypertrophy: in the presence of right ventricular hypertrophy, however, a tall R wave in V5 or V6 of $34 \mathrm{~mm}$.; or an R of $25 \mathrm{~mm}$. or more, when accompanied by a small $\mathrm{S}$ wave or $\mathrm{S}-\mathrm{T}$ depressions and $\mathrm{T}$ inversions, is highly significant and indicates left ventricular hypertrophy. The figure $34 \mathrm{~mm}$. for the $R$ wave in V5 or V6 was that actually observed in our cases and also is the upper limit of normal given by Ziegler (1951). The post-mortem and radiographic studies supported the electrocardiographic concept of the predominance of the right ventricle in these cases.

There were six different vectorcardiographic patterns observed. Three occurred in the presence of combined ventricular hypertrophy and these will be discussed together.

Normal. Thirteen patients had normal vectorcardiograms. Of these, seven were mild cases and two had associated aortic regurgitation but with normal dynamics. Of four patients with normal vectors and moderate or severe degrees of ventricular septal defect, three were infants below seven months of age and one a child aged four. As with the electrocardiogram, interpretation of vectorcardiograms in infants is difficult. A wide range of normal patterns may be observed, including an anterior displacement of the QRSsÊ loop. For this reason we had to consider the vectorcardiogram normal in these four cases.

Right bundle-branch block. This pattern occurred in two patients with mild septal defects and in one with associated aortic regurgitation.

Right ventricular hypertrophy. This pattern was observed in five patients. Of these, three had infundibular pulmonary stenosis and two had moderate to severe septal defects. 
Combined ventricular hypertrophy. There are three basic patterns that we believe represent combined ventricular hypertrophy in congenital heart disease (Fig. 7). They have been designated

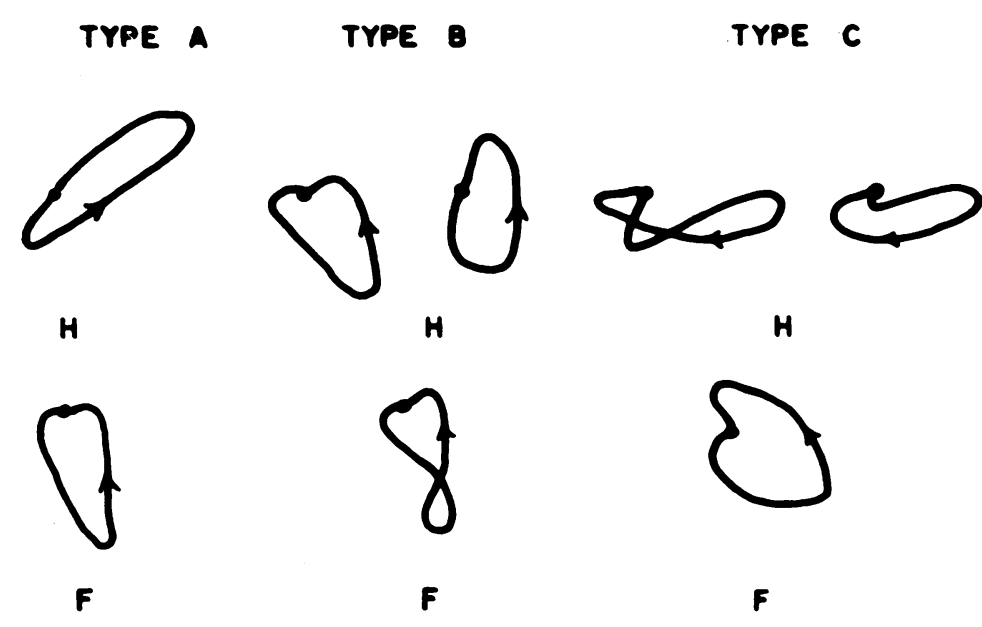

Fig. 7.-Diagrammatic representation of the horizonal $(\mathrm{H})$ and frontal $(\mathrm{F})$ plane QRSsE loops in the three basic patterns of combined ventricular hypertrophy associated with interventricular septal defects.

as type $\mathrm{A}, \mathrm{B}$, and $\mathrm{C}$. In type $\mathrm{A}$, a large initial segment of the QRSsÊ loop in the horizontal plane is directed to the right and anteriorly. The initial segment of the QRSsE loop is usually attributed to septal depolarization, but Cabrera et al. (1958) state that right ventricular activation also may contribute to this portion of the loop, and hence, when it is large, it may signify hypertrophy of the septum, the right ventricle, or both. In type A, after the initial portion of the QRSsE loop, the orientation is leftward and posterior, and the sense of rotation is counterclockwise as in left ventricular hypertrophy. Thus, we feel that this pattern represents combined ventricular hypertrophy.

Type B is a pattern characterized by a large anterior displacement of the QRSsE loop in the horizontal plane, with the main axis in the plus 60 to 90 degrees segment, and counterclockwise in rotation. A greater than normal portion of the loop is anterior to the horizontal axis, signifying right ventricular hypertrophy. The sense of rotation, however, is counterclockwise which we believe, in this instance, signifies additional left ventricular hypertrophy.

In type $C$ the horizontal plane QRSsE loop is similar to a pattern observed with right ventricular hypertrophy. There is a figure of eight QRSsÊ loop in the horizontal plane, with the terminal limb clockwise and anterior to the E point; or a clockwise anteriorly displaced QRSsE loop. However the direction of inscription in the frontal plane is counterclockwise, and the loop displaced to the left, which serves to differentiate these cases from that of pure right ventricular hypertrophy, in which the direction of inscription in the frontal plane is clockwise (Grishman and Scherlis, 1952). This pattern accounts for the presence of right ventricular hypertrophy with left axis deviation that we have observed in the electrocardiograms of some of these cases.

Of the 13 instances of a vectorcardiographic pattern that we consider to represent combined ventricular hypertrophy, 12 occurred in patients with moderate or severe septal defects and only once was this pattern observed in a mild case.

In spite of the fact that there were differences in the interpretation of the vectorcardiogram and electrocardiogram, from the information given a diagnosis of combined ventricular hypertrophy 
could be made in approximately 45 per cent of the patients. Although there was great variation in the electrocardiographic and vectorcardiographic patterns observed, they are sufficiently dissimilar from those observed in other acyanotic congenital lesions to be of diagnostic value and in addition give a clue to the severity of the lesion.

\section{SUMMARY}

Thirty-five cases of ventricular septal defect have been reviewed with special reference to the electrocardiogram and vectorcardiogram.

Except in infants, if the electrocardiogram and vectorcardiogram were normal, a mild case from a clinical and hæmodynamic standpoint could be predicted.

Combined ventricular hypertrophy was found in association with moderate or severe cases.

Right ventricular hypertrophy was usually associated with infundibular pulmonary stenosis or severe pulmonary hypertension.

Isolated left ventricular hypertrophy was a rare finding.

We present the electrocardiographic criteria that we believe are useful for the diagnosis of left ventricular hypertrophy in the presence of right ventricular hypertrophy in ventricular septal defect.

Three vectorcardiographic patterns are described that we believe are indicative of combined ventricular hypertrophy in ventricular septal defect.

We are indebted to Dr. Alvin J. Gordon, chief of the cardiopulmonary unit, who kindly permitted us to use the catheterization data. Miss Ruth Jaspan rendered invaluable help and assistance throughout this study.

\section{REFERENCES}

Barker, J. M., and Valencia, F. (1949). Amer. Heart J., 38, 376.

Braunwald, E., Donoso, E., Sapid, S., and Grishman, A. (1955). Amer. Heart J., 50, 591; 674; 823.

Brotmacher, L., and Campbell, M. (1958). Brit. Heart J., 20, 97.

Cabrera, E., Gaxiola, A., and Eisenberg, P. (1958a). Arch. Inst. Cardiol. Méx., $28,469$.

- , Rodrigues, R., Gaxiola, A., and Portillo, B. (1958b). Arch. Inst. Cardiol. Méx., $28,592$.

Downing, D. F., and Goldberg, H. (1956). Diseases of the Chest, 29, 475.

Fyler, D. C., Rudolph, A. M., Wittenborg, M. H., and Nadas, A. S. (1958). Circulation, $18,833$.

Goodwin, J. F. (1952). Brit. Heart J., 14, 173.

Grishman, A., and Scherlis, L. (1952). Spatial Vectorcardiograhpy. W. B. Saunders Co., Philadelphia.

Heath, D., Brown, J. W., and Whitaker, W. (1956). Brit. Heart J., 18, 1.

Levine, H. D., and Phillips, E. (1951). New Engl. J. Med., 245, 833.

Lipsett, M. B., and Zinn, W. J. (1953). Amer. Heart J., 45, 86.

Mannheimer, E., Ikkos, D., and Jonsson, B. (1957). Brit. Heart J., 19, 333.

Marsico, F., Penaloza, D., Tranchesi, J., Limon, R., and Sodi-Pallares, D. (1955). Amer. Heart J., 49, 188.

Milnor, W. R. (1957). Circulation, 16, 348.

Pagnoni, A., and Goodwin, J. F. (1952). Brit. Heart J., 14, 451.

Roger, H. (1879). Bull. Acad. Méd., Paris, 8, 1074.

Rosenman, R. H., Krause, S., Hwang, W., and Katz, L. N. (1950). Amer. Heart J., 40, 453.

Selzer, A. (1949). Arch. intern. Med., 84, 798.

Sokolow, M., and Lyon, T. P. (1949). Amer. Heart J., 37, 161.

- L (1949). Amer. Heart J., 38, 273.

Taussig, H. B. (1947). Congenital Malformations of the Heart. New York, Commonwealth Fund.

Whipple, G., and Levine, H. (1955). Clin. Research Proc., 3, 109.

Wilson, F. N., Rosenbaum, F. F., and Johnston, F. D. (1954). Selected Papers. Edwards Brothers Inc., Ann Arbor.

Wolf, L., Richman, J. L., and Soffe, A. M. (1953). New Engl. J. Med., 248, 851.

Wood, P., Magidson, O., and Wilson, P. A. O. (1954). Brit. Heart J., 16, 387.

Ziegler, R. F. (1951). Electrocardiographic Studies in Normal Infants and Children. C. Thomas Co., Springfield. 